\title{
Effect of guidelines on management of head injury on record keeping and decision making in accident and emergency departments
}

\author{
Richard Thomson, Jackie Gray, Rajan Madhok, Alan Mordue, A David Mendelow
}

\begin{abstract}
Objective-To compare record keeping and decision making in accident and emergency departments before and after distribution of guidelines on head injury management as indices of implementation.
\end{abstract}

Design-Before (1987) and after (1990) study of accident and emergency medical records.

Setting-Two accident and emergency departments in England.

Patients-1144 adult patients with head injury in department 1 (533 in 1987, 613 in 1990) and 734 in department $2(370,364$ respectively).

Main measures-Recording of relevant symptoms and signs as determined in the guidelines; presence of, indications for, and rates and appropriateness of skull $x$ ray examination and admission.

Results-The median number of guidelines variables recorded for all study periods ranged from 7 to 9 out of a possible maximum of 27 . For key decision making variables the presence or absence of penetrating injury was least likely to be recorded $(\leqslant 1 \%)$ and that of loss of consciousness most likely ( $\geqslant 75 \%)$. Altogether, the proportion of patients receiving skull $\boldsymbol{x}$ ray examination or admitted varied from $25 \%-60 \%$ and $7 \%-23 \%$ respectively; overall, 69\% (1280/1856) and 64\% (1177/1851) of patients were managed appropriately. However, no consistent change occurred in the departments between the study periods. For instance, in department 1 the proportion of appropriate $x$ ray examinations rose significantly after distribution of the guidelines (from 61\% (202/330) to 73\% (305/417)) and appropriate decisions on whether to $x$ ray or not also rose (from 65\% (340/522) to $72 \%$ (435/608)). There was no significant change in department 2 , although the proportion of appropriate admissions fell (from 33\% (55/166) to 15\% (19/130)).

Conclusions-Recording practice and decision making were variable and had not consistently improved after dissemination of the guidelines. Strategies are required to ensure effective implementation of guidelines.

(Quality in Health Care 1994;3:86-91)

\section{Introduction}

The potential of clinical guidelines to improve the quality of patient care has received considerable attention. ${ }^{1-5}$ However, the evidence for effectiveness of guidelines in the United Kingdom is limited, and continuing evaluation of guidelines is therefore essential. Such evaluation should include examination of the processes of development, dissemination, and implementation, as well as the outcomes after application of guidelines. ${ }^{6-12}$

Patients with head injury are at risk of cerebral haematoma and subsequent brain injury. ${ }^{13}$ Appropriate early management of patients with such injury, the commonest single injury seen within accident and emergency departments, ${ }^{14}$ can significantly reduce secondary brain damage if early identification and management of haematoma is achieved. ${ }^{15} 16$ Excessive and inappropriate use of skull $x$ ray examination, and to a lesser extent admission, of head injured patients has been recorded. ${ }^{17}{ }^{18}$ Identifying patients at high risk can both target resources (for instance, the use of $x$ rays and admission for observation) and limit unnecessary interventions. ${ }^{19} 20$

To enhance the quality of care for patients with head injury, guidelines for their management were formulated by a group of neurosurgeons in $1984,{ }^{21}$ drawing on previously published guidelines for skull $x$ ray examination. ${ }^{22}$ These guidelines were adapted in the Northern region, printed on laminated cards and wall posters (box), and distributed by post to all districts and accident and emergency departments from 1988 onwards. They included sections on skull $x$ ray examination, admission, management of patients in coma or with multiple injuries, and consultation with a neurosurgical unit. In a previous study we showed that dissemination of the guidelines was incomplete and variable, although this improved somewhat after changes to the process. ${ }^{24}$ Furthermore, a separate study has demonstrated an increase in the number of haematomas referred and surgically removed. ${ }^{24 a}$

This paper reports a study undertaken to ascertain whether the distribution of the guidelines was followed by change in completion of medical records and in decision making by junior doctors in two accident and emergency departments with respect to skull $x$ ray examination and admission of patients with head injury.

\section{Methods}

SELECTION OF DEPARTMENTS AND PERIOD OF STUDY

The results of the earlier questionnaire survey of doctors' receipt and use of the guidelines ${ }^{24}$ 


\section{Criteria for skull $x$ ray examination} after recent head injury ${ }^{\star}$

Clinical judgement is necessary but the following criteria are helpful:

1 Loss of consciousness or amnesia at any time.

2 Neurological symptoms or signs (including headache/vomiting)

3 Loss of cerebrospinal fluid or blood from the nose or ear

4 Suspecting penetrating injury

5 Scalp bruising or deep laceration

6 Difficulty in assessing the patient (for example, alcohol intoxication, epilepsy, children)

\section{Criteria for admission of adults}

1 Confusion or any other depression of level of consciousness at the time of examination

2 Skull fracture

3 Neurological symptoms and signs

4 Difficulty in assessing the patient (for example, alcohol, epilepsy)

5 Other medical conditions (for example, haemophilia)

6 Patient's social conditions or lack of a responsible adult or relative

Post-traumatic amnesia or unconsciousness with full recovery is not necessarily an indication for admission

Patients sent home should receive advice to return immediately if there is any deterioration

Children may be difficult to assess: admit if in doubt or consult regional neurosurgical unit, or both

^Excerpt from guidelines for the management of patients with recent head injury disseminated within the Northern region. The complete guidelines also included management of patients in coma or with multiple injuries and referral to a neurosurgical unit

were used to identify departments in which junior doctors involved in the initial management of head injury had reported receiving and using the guidelines. Two departments which had attendance registers to enable identification of subjects and where accident and emergency medical records were

All cases of head injury

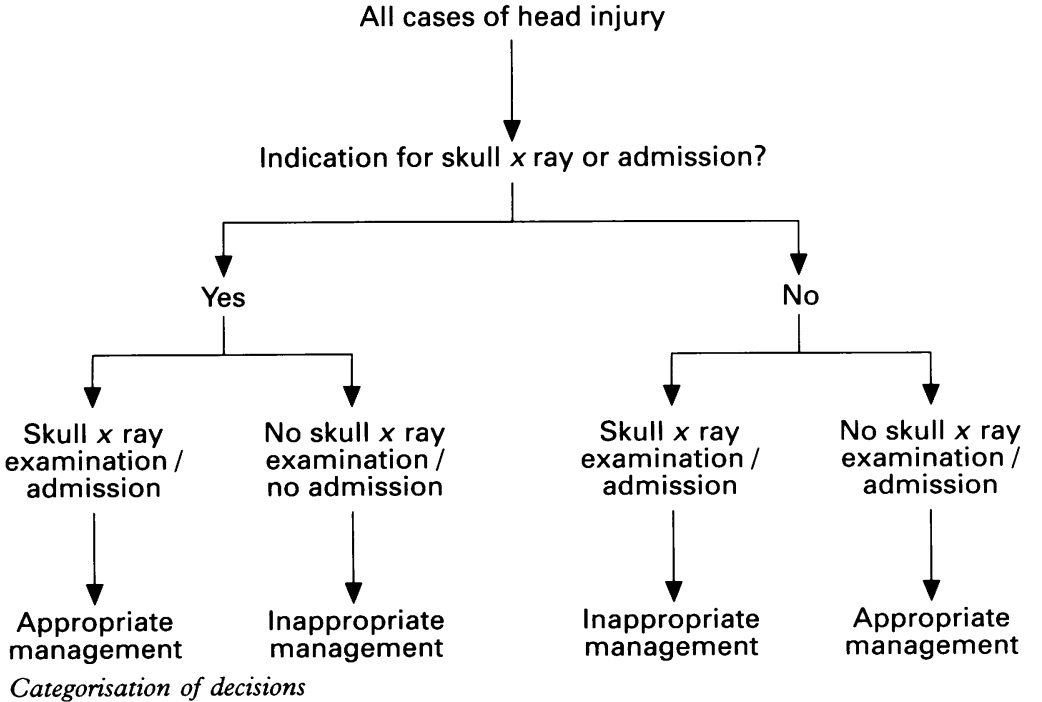

easily accessible were selected. Before and after periods (from 1 February to 31 May) were chosen in 1987 , before distribution of the guidelines, and 1990, at the time of the earlier postal questionnaire, such that we would be studying the accident and emergency records at a time of reported receipt and use of the guidelines. This study period was expected to allow for about 500 subjects in each study period for each department on the basis of previous reports of head injury activity. ${ }^{14}$

\section{DEFINITION OF CASES AND CATEGORISATION} OF DECISIONS

The case definition of head injury was as used in other epidemiological studies. ${ }^{14} \mathrm{~A}$ case was defined as an adult aged 16 years or over presenting with a history of a blow to the head or with altered consciousness after a relevant injury or with a scalp or forehead laceration (patients who had only jaw or facial fractures or foreign bodies in their eyes, ears, or nose were excluded).

An appropriate decision was defined as a decision to perform a skull $x$ ray examination or not or to admit or not, consistent with recorded indications or lack of recorded indications. An inappropriate decision was deemed to have been made if $x$ ray examination or admission occurred in the absence of recorded indications or failed to occur in the presence of a recorded indication (figure).

DATA COLLECTION AND ANALYSIS

For each case the following data were collected from the accident and emergency record of the patient's attendance: age, sex, whether or not the patient had a skull $x$ ray examination or was admitted, and recording of the presence or absence of 25 different clinical terms derived from the guidelines which might have a bearing on the decision to $x$ ray or admit (see table 2). The data were collected by a single researcher (JG) with a standardised proforma. A pilot study of 50 cases in patients presenting outside the study periods was undertaken to assess the feasibility of the proposed method for case ascertainment and data collection. It showed that the process of ascertainment was satisfactory but disclosed the need to reconstruct the proforma to cope with highly variable recording styles among individual doctors. It also showed that retrospective reliable assessment of the presence or absence of two indications for admission in the guidelines - namely, "patient's social conditions or lack of a responsible adult/relative" and "other medical conditions" - which might have influenced admission decisions, was not possible.

The data were entered into a database using DBase III+, and analysis was undertaken with various software packages, including Epi-info, SAS, and Paradox. For each department the results of the two study periods were compared by analysis of proportions or comparison of means, as appropriate. Accuracy of the data within the study database was assessed for 50 cases. Each record had 37 different variables such that a total of 1850 
Table 1 Numbers of cases of head injury, completeness of retrieval of notes, and demographic details of patients

\begin{tabular}{|c|c|c|c|c|}
\hline & \multicolumn{2}{|c|}{ Department 1} & \multicolumn{2}{|c|}{ Department 2} \\
\hline & 1987 & 1990 & 1987 & 1990 \\
\hline $\begin{array}{l}\text { No of possible cases identified from } \\
\text { accident and emergency register }\end{array}$ & 588 & 653 & 513 & 450 \\
\hline $\begin{array}{l}\text { No }(\%) \text { case records retrieved } \\
\text { No }(\%) \text { meeting case definition } \\
\text { Mean age of patient (years) } \\
\text { No }(\%) \text { male }\end{array}$ & $\begin{array}{l}557(95) \\
533(96) \\
37 \cdot 1 \\
316(60)\end{array}$ & $\begin{array}{l}629(96) \\
613(97) \\
38 \cdot 4 \\
402(66)^{\star}\end{array}$ & $\begin{array}{l}405(79) \\
370(91) \\
39 \cdot 7 \\
225(61)\end{array}$ & $\begin{array}{l}385(86) \\
364(95) \\
38 \cdot 4 \\
275(76)^{\star}\end{array}$ \\
\hline
\end{tabular}

${ }^{\star} \mathrm{p}<0.05$.

Table 2 Recording of clinical variables in accident and emergency case notes in two departments before and after distribution of guidelines on management of head injury

\begin{tabular}{|c|c|c|c|c|}
\hline & \multicolumn{2}{|c|}{ Department 1} & \multicolumn{2}{|c|}{ Department 2} \\
\hline & 1987 & 1990 & 1987 & 1990 \\
\hline No of cases & 533 & 613 & 370 & 364 \\
\hline $\begin{array}{l}\text { No of variables recorded per case: } \\
\text { Median } \\
\text { Range } \\
\text { Interquartile range }\end{array}$ & $\begin{array}{l}7 \\
0-19 \\
4-9\end{array}$ & $\begin{array}{l}9 \\
0-18 \\
6-12\end{array}$ & $\begin{array}{l}7 \\
0-15 \\
5-9\end{array}$ & $\begin{array}{l}7 \\
0-17 \\
5-9\end{array}$ \\
\hline
\end{tabular}

$\%$ Of cases for which presence or absence of a key variable was recorded:

\begin{tabular}{|c|c|c|c|c|}
\hline \multicolumn{5}{|c|}{ Symptoms } \\
\hline Loss of consciousness & 75 & $79^{\star}$ & 77 & 77 \\
\hline Amnesia & 12 & 10 & 5 & $12^{\star}$ \\
\hline Drowsiness & 2 & $10^{\star}$ & 29 & $7 \dagger$ \\
\hline Headache & 25 & $44^{\star}$ & 19 & 21 \\
\hline Nausea and vomiting & 57 & $70^{\star}$ & 44 & $59^{\star}$ \\
\hline Visual disturbance & 21 & $37^{\star}$ & 2 & $8^{\star}$ \\
\hline Weakness & 6 & 21 & 3 & 2 \\
\hline Confusion & 2 & 2 & 1 & 1 \\
\hline Vertigo or dizziness & 11 & $19^{\star}$ & 11 & $18^{\star}$ \\
\hline $\begin{array}{l}\text { Leakage of cerebrospinal fluid or blood } \\
\text { from nose or ear }\end{array}$ & 21 & $14 \dagger$ & 4 & 4 \\
\hline Suspicion of penetrating injury & $<1$ & $<1$ & 1 & 1 \\
\hline \multicolumn{5}{|c|}{ Signs } \\
\hline Scalp bruising & 25 & $31^{\star}$ & 17 & 11 \\
\hline Deep laceration & 15 & $32^{\star}$ & 17 & 23 \\
\hline Difficulty in assessing patient & 2 & 2 & 5 & $1 \dagger$ \\
\hline Alcohol intoxication & 11 & 14 & 12 & 11 \\
\hline Epilepsy & 4 & 3 & 1 & 2 \\
\hline Depressed consciousness on examination & 50 & $43 \dagger$ & 53 & $6 \dagger$ \\
\hline Confusion on examination & 46 & $39+$ & 26 & 32 \\
\hline Abnormal pupillary reflexes & 50 & $57^{\star}$ & 56 & 52 \\
\hline Abnormal cranial nerves & 30 & 28 & 12 & 9 \\
\hline Abnormal reflexes & 12 & $34^{\star}$ & 29 & $13+$ \\
\hline Abnormal tone & 6 & $25^{\star}$ & 17 & $10+$ \\
\hline Abnormal power & 21 & $31^{\star}$ & 21 & $11 \dagger$ \\
\hline Abnormal coordination & 1 & $7^{\star}$ & 1 & 1 \\
\hline Abnormal sensation & 3 & $9^{\star}$ & 2 & 3 \\
\hline \multicolumn{5}{|c|}{ Decisions } \\
\hline Admission & 99 & 99 & 98 & 96 \\
\hline Skull $x$ ray examination performed & 98 & 99 & 100 & $98 \dagger$ \\
\hline
\end{tabular}

$\star_{\mathrm{p}}<0.05$.

tp $<0.05$ in direction contrary to expected effect of guidelines.

Table 3 Clinical decision making on the use of skull $\mathrm{x}$ ray examination in two accident and emergency departments before and after distribution of guidelines on management of head injury. Variation in the denominator reflects missing data

\begin{tabular}{|c|c|c|c|c|}
\hline & \multicolumn{2}{|c|}{ Department 1} & \multicolumn{2}{|c|}{ Department 2} \\
\hline & $\begin{array}{l}\text { Before } \\
\text { guidelines } \\
(n=533)\end{array}$ & $\begin{array}{l}\text { After } \\
\text { guidelines } \\
(n=613)\end{array}$ & $\begin{array}{l}\text { Before } \\
\text { guidelines } \\
(n=370)\end{array}$ & $\begin{array}{l}\text { After } \\
\text { guidelines } \\
(n=364)\end{array}$ \\
\hline $\begin{array}{l}\text { No of cases with recorded } \\
\text { indication for } x \text { ray } \\
\text { examination }\end{array}$ & 338 & 421 & 188 & 162 \\
\hline \multirow{2}{*}{$\begin{array}{l}\%(\mathrm{No}) \text { receiving } \\
\text { skull } x \text { ray examination } \\
\% \text { (No) not receiving } \\
\text { skull } x \text { ray examination }\end{array}$} & $61(202 / 330)$ & $73(305 / 417)^{\star}$ & $52(98 / 187)$ & $46(73 / 159)$ \\
\hline & $39(128 / 330)$ & $27(112 / 417)^{\star}$ & $48(89 / 187)$ & $54(86 / 159)$ \\
\hline $\begin{array}{l}\text { No of cases without } \\
\text { recorded indication for } \\
x \text { ray examination }\end{array}$ & 195 & 190 & 182 & 202 \\
\hline \multirow{2}{*}{$\begin{array}{l}\%(\mathrm{No}) \text { receiving } \\
\text { skull } x \text { ray examination } \\
\% \text { (No) not receiving } \\
\text { skull } x \text { ray examination }\end{array}$} & $28(54 / 192)$ & $31(59 / 189)$ & $15(28 / 182)$ & $9(18 / 198)$ \\
\hline & $72(138 / 192)$ & $69(130 / 189)$ & $85(154 / 182)$ & $91(180 / 198)$ \\
\hline $\begin{array}{l}\%(\mathrm{No}) \text { of cases managed } \\
\text { appropriately }\end{array}$ & $65(340 / 522)$ & $72(435 / 606)^{\star}$ & $68(252 / 369)$ & $71(253 / 357)$ \\
\hline
\end{tabular}

${ }^{\star} \mathrm{p}<0 \cdot 05$. variables was studied. Two errors were found, representing an error rate of $0 \cdot 1 \%$.

\section{Results}

Table 1 shows numbers of cases, completeness of retrieval of notes, and basic demographic details.

CLINICAL RECORDING

The median number of clinical variables recorded for each case did not change significantly in either department after introduction of the guidelines and ranged from 7 to 9 variables across the four study periods (table 2). The percentage of cases for which the presence or absence of each key variable was recorded in the accident and emergency notes varied widely, from less than $1 \%$ for suspicion of penetrating injury to $79 \%$ for loss of consciousness (table 2). In each department between the before and after study periods there were both significant rises and falls in the level of recording for individual key variables in decision making. Thus in department 2, although the recording of presence or absence of nausea and vomiting increased significantly, the rate of recording for presence or absence of abnormal reflexes or abnormal power fell significantly. Although the recording of presence or absence of abnormal tone improved significantly in department 1 , it fell in department 2. Nevertheless, in both departments the recording of whether the patient had a skull $x$ ray examination or was admitted was clearly identifiable in more than $95 \%$ of cases.

CLINICAL DECISION MAKING

Between the two study periods the overall percentage of cases in which patients had a skull $x$ ray examination rose in department 1 (from $49 \%(256 / 522)$ to $60 \%(365 / 606)$, but fell in department 2 (from 34\% (126/369) to $25 \%(91 / 357)$ (table 3 ). In department 1 the total number of patients having a skull $x$ ray examination appropriately rose significantly. This predominantly reflects an increase in the number with a recorded indication for skull $x$ ray examination who subsequently received it, although there was a non-significant increase in the number without a recorded indication who also received a skull $x$ ray examination. In department 2 there was no significant change in the appropriateness of decision making with respect to skull $x$ ray examination.

The overall percentage of admissions ranged from $7 \%(25 / 351)$ in the second study period in department 2 to $23 \%(140 / 606)$ in the second study period in department 1 (table 4). The percentage of patients admitted between periods in department 2 fell significantly. The overall proportion of cases managed appropriately with respect to admission varied little across the two departments. The proportion of patients without an apparent indication for admission who were nevertheless admitted in either department remained unchanged after introduction of the guidelines, but the 
Table 4 Clinical decision making on patient admission in two accident and emergency departments before and after distribution of guidelines on management of head injury. Variation in the denominator reflects missing data

\begin{tabular}{|c|c|c|c|c|}
\hline & \multicolumn{2}{|c|}{ Department 1} & \multicolumn{2}{|c|}{ Department 2} \\
\hline & $\begin{array}{l}\text { Before } \\
\text { guidelines } \\
(n=533)\end{array}$ & $\begin{array}{l}\text { After } \\
\text { guidelines } \\
(n=613)\end{array}$ & $\begin{array}{l}\text { Before } \\
\text { guidelines } \\
(n=370)\end{array}$ & $\begin{array}{l}\text { After } \\
\text { guidelines } \\
(n=364)\end{array}$ \\
\hline $\begin{array}{l}\text { No of cases with recorded } \\
\text { indication for admission }\end{array}$ & 288 & 355 & 170 & 141 \\
\hline $\begin{array}{l}\% \text { (No) admitted } \\
\% \text { (No) not admitted }\end{array}$ & $\begin{array}{l}34(96 / 285) \\
66(189 / 285)\end{array}$ & $\begin{array}{l}36(128 / 352) \\
64(224 / 352)\end{array}$ & $\begin{array}{l}33(55 / 166) \\
67(111 / 166)\end{array}$ & $\begin{array}{l}15(19 / 130)^{\star} \\
85(111 / 130)^{\star}\end{array}$ \\
\hline $\begin{array}{l}\text { No of cases without } \\
\text { recorded indication for } \\
\text { admission }\end{array}$ & 245 & 255 & 200 & 223 \\
\hline $\begin{array}{l}\% \text { (No) admitted } \\
\% \text { (No) not admitted }\end{array}$ & $\begin{array}{c}6(15 / 242) \\
94(227 / 242)\end{array}$ & $\begin{array}{c}5(12 / 254) \\
95(242 / 254)\end{array}$ & $\begin{array}{c}3(5 / 198) \\
97(193 / 198)\end{array}$ & $\begin{array}{c}2(4 / 221) \\
98(217 / 221)\end{array}$ \\
\hline $\begin{array}{l}\%(\mathrm{No}) \text { of cases managed } \\
\text { appropriately }\end{array}$ & $61(323 / 527)$ & $61(370 / 606)$ & $68(248 / 364)$ & $67(236 / 351)$ \\
\hline
\end{tabular}

${ }^{\star} \mathrm{p}<0.05$.

proportion with a recorded indication for admission who were admitted to department 2 fell significantly (table 4).

\section{Discussion}

This study assessed the impact of guidelines on junior doctors' clinical recording practice and decision making with respect to patients with head injury. We expected that introducing the guidelines in two accident and emergency departments in which doctors had reported receiving and using them ${ }^{24}$ would have led to an increased recording of key decision making variables and an increase in appropriate (or a decrease in inappropriate) decision making.

CLINICAL RECORDING

We were concerned to find evidence of incompleteness of clinical records. Although the level of recording of the presence or absence of individual clinical variables changed significantly before and after introduction of the guidelines in both departments, the importance, size, and direction of the changes varied between and within the departments and were inconsistent with the expected effects of the guidelines. Given that the structure of accident and emergency record cards was not changed in either department between the study periods and given the inconsistency in the direction of change of recording practice, the changes in individual variables probably reflect differences in the recording practices of individual junior doctors rather than any influence as a result of the guidelines themselves.

The level of clinical recording in the written accident and emergency notes may not accurately reflect the extent of the history and examination performed by the junior doctors, particularly when the majority of cases are of minor head injury. However, this should not affect the hypothesis that clinical recording of key variables might be expected to increase, given that the junior doctors themselves had reported using the guidelines.

The level of recording has other important implications. Lack of clearly recorded decision making criteria could have medicolegal implications. Equally, there are implications for retrospective research or audit studies using accident and emergency records as a source of data. Perhaps most importantly, there are implications for subsequent patient care, including evaluation of progress.

CLINICAL DECISION MAKING

In this study individual decision making variables were given equal weight. Clearly, decisions on some clinical signs or symptoms are more open to clinical judgement than others. We cannot therefore make a precise judgement on any individual clinical case from the data collected in this study. None the less, our results give some cause for concern.

The overall rate of skull $x$ ray examination in patients with head injury varied over time and between departments (table 3). Nevertheess, the proportion of patients receiving a skull $x$ ray examination in both departments (overall $838 / 1856,45 \%$ ) was lower than that observed in most other studies, where it ranged from $50 \%$ to $81 \% .^{25-27}$ However, a recent study found a lower overall rate of $20.5 \% .{ }^{28}$

Again, despite a pronounced and significant increase in the proportion of cases with an indication appropriately given a skull $x$ ray examination in department 1 , the change in overall appropriateness was less pronounced, and no such changes were seen in department 2. In an earlier study assessing appropriateness of skull $x$ ray examination ${ }^{27}$ a higher percentage of patients without guidelines indications received a skull $x$ ray examination than in our study ( $9 \%$ to $31 \%$ ) whereas in a more recent study only one patient in 405 received a skull $x$ ray examination inappropriately. ${ }^{29}$

If all decisions for skull $x$ ray examination had been made appropriately there would have been $1109 x$ ray examinations, compared with the 838 actually done (of which 159 were inappropriate). Thus more appropriate decision making could lead to more $x$ ray examinations overall, but this would be offset by the clinical benefits and the reduction of inappropriate exposure of patients to radiation.

The admission rates varied across both departments and time periods and the only significant change in department 2 (in the admission rate), was contrary to that expected if the guidelines had been effective, although the rate of inappropriate admission was low in all study periods. The appropriate and inappropriate admission rates in our study are within the range of admissions previously reported across nine centres (49\% (range $22-71 \%$ ) of cases with indications and $14 \%$ (range $1-20 \%$ ) without indication ${ }^{18}$ ).

The reasons for a decision for skull $x$ ray examination or admission might be expected to have been recorded. In particular, the large number of $x$ ray examinations performed without apparent indication is of some concern. Either junior doctors are not recording the reasons for a decision or decisions are being taken despite the absence of indications. 
The proportion of admissions without a recorded indication was much lower than that for skull $x$ ray examination; some may have been for social reasons or for other medical conditions, which proved impossible to assess from the records in the pilot study. A recent study reported an overall prevalence of $5.6 \%$ of social or other medical reasons for admission in those presenting with head injury (similar to our proportion of cases inappropriately admitted). ${ }^{29}$ The relatively high proportion of patients not admitted despite a recorded indication suggests either that indications are being ignored or that clinical judgements are being made about the importance of particular indications in individual cases. Thus, the indication "abnormal neurological symptoms or signs" could cover a variety of features from the relatively trivial to the clearly clinically severe. This reflects an important feature of guidelines - namely, that some elements of guidelines should rightly leave flexibility for clinical judgement on individual cases. It might be preferable for the guidelines to be clear about this - for instance, stating which, if any, indications are absolutes (or rules).

This study showed that despite the dissemination and reported receipt and use of guidelines, there was no overall change consistent with the guidelines in either recording practice or decision making. This re-emphasises the importance of appropriate (local) implementation strategies for guidelines, a point well made in the reviews of Russell and Grimshaw." "Local endorsement of guidelines, among other factors, is probably critical in supporting their implementation. Although we did not formally assess such factors, during the course of the study we observed notable differences between the two departments, including differences in management styles, culture, and workload, as well as in informal policies on nocturnal skull radiography. It was our impression that these factors may have been influential in determining the extent to which junior doctors were encouraged to follow the guidelines. The impression of the person collecting the data (JG) in this study was that in department 1 the guidelines were supported and encouraged by the head of the department whereas in the other department the guidelines were apparently less prominently displayed and supported.

In view of these findings the following are recommended.

(1) The use of structured record forms to support patient specific reminders at the time of patient encounter should be considered.

(2) Local consultants should endorse guidelines and encourage their use, preferably through educational initiatives. ${ }^{6} 9$

(3) Local evaluation through local audit programmes could further support implementation of guidelines.

(4) It is insufficient to rely on an effective dissemination process alone to ensure the effective application of guidelines.

(5) The introduction of guidelines in whatever setting should preferably include a prospective scheme to evaluate their development, dissemination, and implementation. We were able to undertake only a retrospective uncontrolled before and after study, with associated limitations in interpretation and power."

This problem has recently been further discussed in a critique of a multicentre audit of abortion services. ${ }^{30} 31$ We have not sought to attribute causation in our study. Indeed, if there had been consistent change in line with the guidelines recommendations it would have been difficult to attribute that change to the guidelines with any confidence. Nevertheless, these findings are important in demonstrating lack of consistent change. Clearly, more is needed to change practice than the present system of dissemination.

As a result of this study and associated work the content of the guidelines (which now include details on management of head injury in children and on advanced life support), have been reviewed, improvements have been made in the dissemination process, ${ }^{2+}$ and discussion is ongoing to enhance the implementation of these guidelines locally and regionally

We thank the staff of the two departments for their help, and Astrid McIntyre for her help with the manuscript.

1 Jenkins 1). Investigations: how to get from guidelines to protocols. BMF 1991:303:323-4.

Haines A, Feder G. Guidance on guidelines. B.MT 1992;305:785-6.

(irol R. Implementing guidelines in general practice care. Quality in Health Care 1992;1:18491.

Clinical Resource and Audit Group cilinical sudimes. Edinburgh: Scottish Office, 1993.

Sheldon TA, Borowitz M. Changing the measure of quality in the NHS: from purchasing activity to purchasing in the NHS: from purchasing activity to pur

Russell IT, Grimshaw J. The effectiveness of referral guidelines: a review of methods and findings of published evaluations. In: Roland $\mathrm{M}$, Coulter A, eds. Hospital referrals. Oxford: Oxford Lniversity Press, 1992.

Grimshaw J, Russell I. Effect of clinical guidelines on medical practice: a ststematic review of rigorous evaluations. Lancet 1993;3+2:1317-22

Grimshaw J, Russell I. Achieving health gain through clinical guidelines. I. Developing scientifically valid guidelines. Quality in Health Cur 1993;2:2+3 8 .

9 Crimshaw JN, Russell IT. Achieving health gain through clinical guidelines. II. Ensuring that guidelines change medical practice. Quality in Health (ar 199:4;3:45-52.

10 Eddy DM. A manual for assessing health pratices and designing practice policics. Pennsylvania: American College destgning practice pollicis

11 Field MJ, Lohr KN. Climical practici guidelines. Dircetions for a newe program. Washington: National Academy Press,

12 Gray JD, Thomson RG, Madhok R, Mordue A, Mendelow AD. Evaluating clinical guidelines. In: Chan JFI. ed. Quality and its applications. Newcastle upon Trne; Penshaw Press, 1993

13 Mendelow AD, Teasdale G, Jennett B, Briden J, Hessett C, Murray G. Risks of intracranial haematoma in head injured adults. $B M 71983 ; 287: 11736$

14 Jennett B, MacMillan R. Epidemiologe of head injurs. BMY 1981;282:101-4.

15 Rose J, Valtonen S, Jennett B. Aroidable factors contributing to death after head injury. BMF 1977; ii:615-8.

16 Mendelow AD, Karmi M\%, Paul KS, Fuller GA, Gillingham FJ. Extradural haematoma: effect of delaved Gillingham FJ. Extradural haem

17 Royal College of Radiologists. A study of utilisation of skull radiography in nine accident and emergency units in the UK. Lancet 1980;ii: 12347 .

18 Fowkes FGR, Ennis WP, Evans RC, Roberts (J, Williams I.A. Admission guidelines for head injuries: variance with clinical practice in accident and emergency units in the UK. BrF Surg 1986;73:891 3.

19 Clarke JA, Adams JE. The application of clinical guidelines for skull radiography in the accident and emergency department: theory and practice. (:Iin Rudiol 1990); $41: 152-5$.

20) Fowkes FGR, Williams LA, Cooke BRB, Evans RC, Gehlbach SH, Roberts CJ. Implementation of guideline for the use of skull radiographs in patients with head injuries. Lancet 1984:ii:795-6. 
21 Group of Neurosurgeons. Guidelines for initial Group of Neurosurgeons. Guidelines for initial
management after head injury in adults. $B M Y$

22 Evans KT, Roberts CJ, Ennis WP. Head injuries in adults. $B M F$ 1983;287:1882-3.

23 Royal College of Radiologists. Patient selection for skul radiography in uncomplicated head injury. Lancet 1983;i:115-8.

24 Madhok R, Thomson RG, Mordue A, Mendelow AD, Barker $J$. An audit of the distribution and use of guidelines for the management of head injury. Quality in Health Care 1993;2:27-30.

24a Treadwell L, Mendelow AD. Audit of head injury management in the Northern region. British fournal of Nursing 1994;3:136-40.

25 Brookes M, MacMillan R, Cully S, Anderson E, Murray S Mendelow $\mathrm{AD}$, et al. Head injuries in accident and emergency departments. How adults? F Epidemiol Community Health 1990;44:147-51.
26 The Scottish head injury management study. Head injuries in Scottish hospitals. Lancet 1977; ii:696-8.

27 De Lacey G, McCabe M, Constant O, Welch T, Spinks C McNally E. Testing a policy for skull radiography (and admission) following mild head injury. $B r f$ Radiol 1990;63:14-8

28 Maclaren RE, Ghoorahoo HI, Kirby NG, Skull x-ray after head injury: the recommendations of the Roval College of Surgeons Working Party Report in practice. Arch Emerg Med 1993;10:138-44.

29 MacLaren RE, Ghoorahoo HI, Kirby NG. Use of an accident and emergency department observation ward in the management of head injury. Br $\mathcal{F}$ Surg 1993 80:215-7.

30 Penney GC, Glasier A, Templeton A. Multicentre criterion based audit of the management of induced abortion in Scotland. $B M F$ 1994;309:15-8.

31 MacRae K. Commentary: validity of assessing change through audit. $B M F$ 1994;309:18-9. 